\title{
Rubber Stiffness Optimization for Floor Vibration Attenuation of a Light Bus Based on Matrix Inversion TPA
}

\author{
Hui Shi $\mathbb{D}^{1}{ }^{1}$ Wenku Shi, ${ }^{1}$ Changhai Yang, ${ }^{1}$ Guozheng Liu, ${ }^{2}$ Zhaomeng Fan, ${ }^{3}$ \\ and Zhiyong Chen ${ }^{1}$ \\ ${ }^{1}$ State Key Laboratory of Automotive Simulation and Control, College of Automotive Engineering, Jilin University, \\ Changchun 130022, China \\ ${ }^{2}$ SAIC Volkswagen Automotive Co., Ltd., Shanghai 201805, China \\ ${ }^{3}$ United Automotive Electronic Systems Co., Ltd, Shanghai 310000, China
}

Correspondence should be addressed to Hui Shi; shihui19892006@126.com

Received 5 October 2020; Revised 9 December 2020; Accepted 14 December 2020; Published 23 December 2020

Academic Editor: Jiaxi Zhou

Copyright $\odot 2020$ Hui Shi et al. This is an open access article distributed under the Creative Commons Attribution License, which permits unrestricted use, distribution, and reproduction in any medium, provided the original work is properly cited.

\begin{abstract}
The NVH characteristics of light buses are a very important performance for market competitiveness. To solve the serious floor vibration of a light bus at speed of $60 \mathrm{~km} / \mathrm{h}$ and $90 \mathrm{~km} / \mathrm{h}$, we first derive the matrix inversion TPA (MITPA) method, and then transfer path contribution is analyzed by applying matrix inversion TPA with TPA model establishment, operational vibration test, and FRF measurement. Next, the energy decoupling rate of the powertrain mount system (PMS) is optimized by rubber stiffness optimization based on the path contribution analysis taking both amplitude and phase into consideration. The optimized natural frequencies and energy decoupling rate indicate that energy decoupling rate (EDR) of each DoF of the powertrain mount system is improved. Finally, to verify the optimization effect, this paper implements an operational vibration test with optimized mount installed. The results indicate that floor vibration of postoptimization is improved significantly compared with that of preoptimization. This paper offers a method for engineers to improve vibration problem of vehicle by combining experimental TPA for identification of dominant paths with optimization procedure.
\end{abstract}

\section{Introduction}

The automotive NVH characteristics are one of the main performances, which affects the vehicle quality and directly determines its market competitiveness. Furthermore, according to the statistical data, one-third of the vehicle failures are related to $\mathrm{NVH}$ problems. Therefore, many automotive manufacturers and researchers have devoted much effort to enhance the NVH performance of automotive. Currently, the techniques to improve the $\mathrm{NVH}$ performance of vehicles are generally divided into numerical methods (such as multibody dynamic method $[1,2]$ (MBD), finite element method [3] (FEM), and boundary element method (BEM)) and experimental methods [4] (such as the spectrum analysis and transfer path analysis (TPA) methods [5-7]); the numerical methods are usually used to analyze or predict the vibration and noise response $(\mathrm{N} \& \mathrm{~V})$ under some excitation sources by numerical models. However, the numerical models are established based on some condition assumptions, which cannot reflect the real conditions of a physical automotive system. Therefore, much intrinsic error is inevitable, which causes inaccurate response prediction. Compared with numerical methods, experimental methods are more accurate, which are all based on physical automotives, especially the TPA method. TPA, as an experiment based methodology, is used to troubleshoot key factors aggravating $\mathrm{N} \& \mathrm{~V}$ problems in practical automotive engineering. There are three kinds of transfer path analysis methods: conventional TPA [8], component-based TPA, and transmissibility-based TPA. For component-based TPA, the first step is to solve blocked force or equivalent force, which characterizes the source by measurements in situ $[9,10]$. Therefore, it is 
independent of the substructure property and is suitable to be used to predict structure-borne sound or vibration of the assembly system [11] with optimized substructure by multiplying blocked forces with measured assembly FRFs, substructuring synthesized $[12,13]$ or numerically simulated. However, it cannot enhance N\&V problems by being combined with optimizing the resilient isolators of the assembly system. For transmissibility-based TPA, FRF measurement is usually not required, especially operational TPA [14, 15]; therefore, it is highly efficient and costs not much time. However, this advantage brings in the disadvantages: possibility of missing important path and cross talk [16]. These two kinds of TPA are more likely to be used in the assembly system for path analysis. And, they are not suitable to be combined with optimizing the resilient isolators. Therefore, for vibration systems, which consist of active source substructure (such as the powetrain system), resilient isolators (such as rubber mounts), and receiver substructures (such as the automotive body), such as light buses, it prefers to use conventional TPA combining with optimizing resilient isolators to troubleshoot NVH problems. Among three different conventional TPA methods, matrix inversion TPA is the most popular one. It requires dismounting the active sources when FRFs are measured by the impact test. Therefore, it would need a little more cost. However, it can obtain very accurate analysis results. During the calculating procedure, measurement errors would be amplified in FRF matrix inversion because of ill-conditioning [17]. Much research has been carried out to improve the ill-conditioning of matrix inversion by singular value decomposition (SVD). For NVH refinement of automotives, much attention has been paid to optimization design of PMS [18-23]; however, there is little research on combining TPA for dominant path identification with optimization design of resilient mounts.

The goal of this paper is to present a solution method to solve the floor vibration problem of light buses, in which the method combines matrix inversion TPA for identification of path contribution with the optimization of energy decoupling rate of PMS. The paper derives the theory of matrix inversion TPA by dynamic substructuring theory first, and then MITPA is applied to analyze the dominant path contribution of the floor vibration problem in light buses. Next, based on path contribution analysis, rubber stiffness is selected to optimize energy decoupling rate of each DoF of PMS. Finally, the operational vibration test with optimized rubber installed is implemented to verify the optimization effect.

This paper starts with a theoretical derivation of matrix inversion TPA in Section 2. Based on the theory of MITPA, Section 3 presents the TPA application procedure and the evaluation method for path contribution analysis. In Section 4 , energy decoupling rate is optimized to improve the vibration isolation performance of PMS. Section 5 verifies the optimization effect by comparing the vibration level of postoptimization with that of preoptimization. The paper is concluded with a summary in Section 6 .

\section{Matrix Inversion TPA Theory}

For vibration systems, they usually consist of active excitation source (such as the powertrain system of a vehicle), transfer paths (such as the vehicle body and frame), and receiver substructures (such as the passenger seats and the floor or the steering wheels). From the concept of "sourcepath-receiver," for floor vibration problems of light buses, the powertrain system can be seen as active excitation source, bus body and frame as vibration transfer paths, and floor as receiver structure. Theoretically, response vector of receiver DoFs can be calculated by superposing path contribution vectors, which are obtained by multiplying vector of source load DoFs by FRF matrix of transfer paths. Therefore, response of receiver DoFs can be expressed as

$$
y_{k}=\sum_{i} H_{i k}(\omega) F_{i}(\omega)
$$

where $y_{k}$ denotes response of the $k^{\text {th }}$ receiver DoF contributed by all source load DoFs transmitted through the $k^{\text {th }}$ transfer path; $H_{i k}(\omega)$ indicates frequency domain transfer functions of the $i^{\text {th }}$ source DoF transmitted through the $k^{\text {th }}$ transfer path; and $F_{i}(\omega)$ indicates the load of the $i^{\text {th }}$ source DoF or interface DoF. Actually, all source DoFs, interface DoFs, and receiver DoFs contain a large set of DoFs, representing, respectively.

Source DoFs: actually, internal DoFs belong to active excitation substructure; practically, they are unmeasurable.

Interface DoFs: coupling DoFs belong to the interface between active source and receiver substructures.

Receiver DoFs: interested response DoFs on receiver substructures, which might be sound pressure, acceleration, or other physical quantities.

Usually, source substructure is coupled with receiver substructures rigidly or by a resilient connector (such as the rubber mount in a PMS). Here, vibration assembly systems coupled by resilient connectors can be illustrated by a diagrammatic sketch, as shown in Figure 1. In Figure 1, A denotes the active source substructure; $B$ denotes the receiver substructure; $S$ denotes the assembly system; $k_{n}$ is the $n^{\text {th }}$ resilient connector. $f_{1}$ is the excitation load of internal DoF; $u_{3}$ is the interested response of receiver substructure; $u_{4}$ is the indicator DoFs.

Therefore, if the vibration problem is approached for the assembly system (as shown in Figure 1(a)), $F_{i}(\omega)$ is the load of the $i^{\text {th }}$ internal DoF of source substructure; $y_{k}$ is the response of the $k^{\text {th }}$ receiver DoF on receiver substructure, and $H_{i k}(\omega)$ is the transfer function from the $i^{\text {th }}$ internal DoF to $k^{\text {th }}$ receiver DoF.

As the denotation in Figure 1, equation (1) can be written as

$$
u_{3}(\omega)=H_{13}^{S}(\omega) f_{1}(\omega) .
$$

If we present the assembly system by decoupling it into individual subsystems, as shown in Figure 1(b). By dynamic substructure theory, equation (2) can be expanded into the subsystem transfer function matrix, which yields 


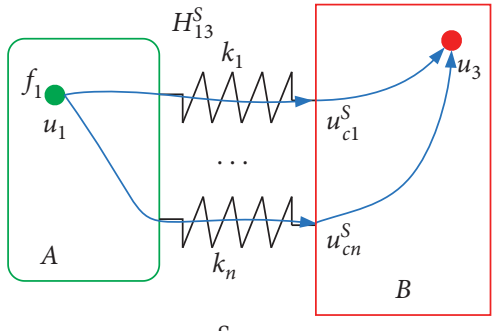

(a)

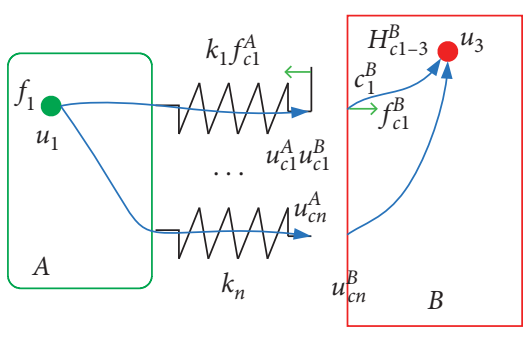

(b)

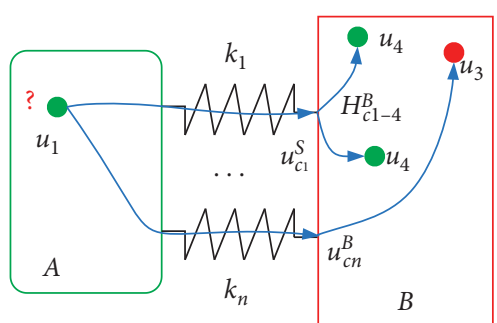

(c)

Figure 1: The MITPA theory illustrated by the diagrammatic system.

$$
\left[\begin{array}{l}
u_{1} \\
u_{c 1}^{A} \\
u_{c 1}^{B} \\
u_{3}
\end{array}\right]=\left[\begin{array}{cccc}
H_{11}^{A} & H_{1 c 1}^{A} & 0 & 0 \\
H_{c 11}^{A} & H_{c 1 c 1}^{A} & 0 & 0 \\
0 & 0 & H_{c 1 c 1}^{B} & H_{c 13}^{B} \\
0 & 0 & H_{3 c 1}^{B} & H_{33}^{B}
\end{array}\right]\left(\left[\begin{array}{c}
f_{1} \\
0 \\
0 \\
0
\end{array}\right]+\left[\begin{array}{c}
0 \\
f_{c 1}^{A} \\
f_{c 1}^{B} \\
0
\end{array}\right]\right)
$$

The compatibility and equilibrium condition should be satisfied in decoupling the assembly system $S$ as following equations:

$$
\left\{\begin{array}{l}
u_{c 1}^{B}=u_{c 1}^{A}, \\
f_{c 1}^{A}=-f_{c 1}^{B} .
\end{array}\right.
$$

Combining equations (3) and (4), it can be derived that

$$
\begin{aligned}
f_{c 1}^{B} & =\left(H_{c 1 c 1}^{A}+H_{c 1 c 1}^{B}\right)^{-1} H_{c 11}^{A} f_{1}, \\
u_{3} & =H_{3 c 1}^{B} f_{c 1}^{B}=\underbrace{\left[H_{3 c 1}^{B}\left(H_{c 1 c 1}^{A}+H_{c 1 c 1}^{B}\right)^{-1} H_{c 11}^{A}\right]}_{H_{31}^{s}} f_{1},
\end{aligned}
$$

where $u$ indicates the response in subsystem $A$ or $B ; H_{i j}^{A}$ or $H_{i j}^{B}$ indicates the transfer matrix of the point $i$ on subsystem $A$ or $B$ to point $j ; f_{k}^{A}$ or $f_{k}^{B}$ indicates the excitation force at point $k$ of subsystem $A$ or $B$.

It can be seen from equation (3) that the response of the passive subsystem depicted by the interface force is equivalent to that caused by excitation force of the active subsystem (the load $f_{1}$ in Figure 1). Therefore, the last two rows of equation (3) can be also written as

$$
\left[\begin{array}{c}
u_{c 1}^{B} \\
u_{3}
\end{array}\right]=\left[\begin{array}{c}
H_{c 1 c 1}^{B} \\
H_{3 c 1}^{B}
\end{array}\right] f_{c 1}^{B}
$$

The same as point 3 in equation (6), the response of indicator point 4 can be expressed as

$$
\begin{aligned}
& u_{4}=H_{41}^{S} f=H_{4 c 1}^{B} \underbrace{\left(H_{c 1 c 1}^{A}+H_{c l c 1}^{B}\right)^{-1} H_{c 11}^{A} f_{1}}_{f_{c 1}^{B}}, \\
& f_{c 1}^{B}=\left(H_{4 c 1}^{B}\right)^{+} u_{4},
\end{aligned}
$$

where $u_{4}$ is the displacement (or other physical quantities) of indicator point 4 and $H_{41}^{S}$ is the transfer function matrix from point 4 to point 1 in the assembly system $S$.

For equation (8), the active excitation system needs to be removed to obtain the transfer function matrix. The elements in the transfer function matrix are usually the same structure; therefore, the transfer function matrix is usually ill-conditioned. Therefore, the number of indicator points should be much larger than the number of interface forces for FRF measurement, which can guarantee that the transfer function matrix $H_{4 c 1}^{B}$ is over determined and has a good condition number. Therefore, the rank of matrix $H_{4 c 1}^{B}$ is full enough to solve the interface force and the condition number is so small reasonably that the measurement error will not be amplified by matrix inversion operation. In general, the indicator DoFs and twice interface force DoFs can bring a good condition number of matrix inversion. The extra effort is bigger than the benefit when adding more indicator DoFs.

A good solution of interface force will be obtained when the number of indicator points is greater than twice the number of response points. To improve the ill-condition of transfer function matrix $H_{4 c 1}^{B}$ inversion, which is a common inverse problem with many good solution methods, singular value decomposition (SVD) $[24,25]$ is a practically used method.

For the transfer function matrix $H_{4 c 1}^{B}$ obtained by the operational test, the singular value decomposition is applied to solve the matrix inversion, and then the interface forces are calculated by solving equation (9). Substituting the obtained interface forces into equation (2), the vibration contribution of each path can be solved. We call this TPA the matrix inversion TPA (MITPA).

As the explanation for equation (1), it can be seen that the main work of TPA is to obtain the frequency response function (transfer function matrix $H_{i k}(\omega)$ ) and identify the interface loads. Usually, the TPA work flow can be divided into four steps: (a) acquiring the operational vibration data, the path points, indicator points, and the response points; (b) determining the transmission property (commonly in ways of FRFs); (c) identifying the operational interface loads between the active and passive sides; (d) calculating the contribution of each transfer path. The FRFs are generally acquired by the direct measurement method or reciprocal measurement method; interface loads can be identified by 


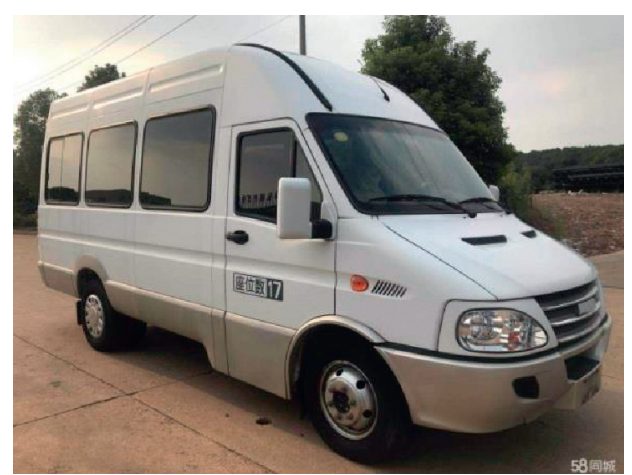

Figure 2: The physical light bus studied.

the direct force method, mount stiffness method, and matrix inversion method.

\section{Vibration Analysis of Light Bus by MITPA}

3.1. Problem Description. When the studied light bus (as shown in Figure 2) is running at a speed of $60 \mathrm{~km} / \mathrm{h}$ and $90 \mathrm{~km} / \mathrm{h}$, the floor vibration is severe, especially the vibration of the rear seat floor (RSF) above the rear axle; therefore, the passenger ride comfort is poor. To improve this problem, the MITPA aforementioned is applied to analyze the vibration contribution of each transfer path; furthermore, the dominant paths are determined. As mentioned in Section 2, there are four steps for an MITPA analysis. In next sections, the vibration problem of the studied light bus is analyzed by the MITPA according to the four steps to find the dominant transfer path, which would lay a foundation for the optimization procedure in Section 4. The work flow is elaborated below.

\subsection{Vibration Analysis by TPA}

3.2.1. TPA Model Establishment. According to the MITPA theory, the source excitation input DoFs can be modeled to be nine DoFs of three engine mount passive side DoFs, four input DoFs of front/rear suspension, three input DoFs of the exhaust system, and two input point DoFs of driveshaft; and one response point with three DoFs is selected to be at the interface between the rear seat and the connected floor above the rear axle. Therefore, there are totally fifty-four transfer paths (multiplying eighteen excitation input DoFs by three response output DoFs is fifty-four transfer paths). The established TPA model is shown in Figure 3.

3.2.2. Operational Vibration Test. For the operational vibration test, the indicator DoFs require twice number the source input DoFs. Therefore, one tri-accelerometer is placed at the response point. Two tri-accelerometers are placed near the corresponding passive side of each mount. All twice-number accelerometer DoFs of source input DoFs are placed near the corresponding passive sides of other sources.

Test condition: first, the light bus is accelerated constantly from startup to $60 \mathrm{~km} / \mathrm{h}$; then, the light bus is kept running at a constant speed of $60 \mathrm{~km} / \mathrm{h}$, and the vibration data acquisition system is started; the time domain data for $20 \mathrm{~s}$ are acquired; totally, three sets of vibration data are acquired. For the speed of $90 \mathrm{~km} / \mathrm{h}$, the same data test operation is implemented. Then, the applicable vibration data of $60 \mathrm{~km} / \mathrm{h}$ and $90 \mathrm{~km} / \mathrm{h}$ are calculated by averaging the three-set data, respectively. After that, the operational vibration data of frequency domain is obtained by Fourier transformation of time domain data.

For limited space, only some test results are shown. Figure 4 shows the two indicator accelerometers' placement near the passive side of rear mount of the powertrain system. Figure 5 shows some operational vibration test results of indicator DoFs and response DoFs.

3.2.3. FRF Measurement. According to the theory of MITPA, it requires to dismantle all the excitation sources from the receiver substructures when the FRFs are measured by the hammer impact test. Therefore, the powertrain system, the exhaust system, the drive shaft, and the suspension system should be dismantled from the bus body and frame. For the simplicity and limited space, the paper only shows the dismantling of the powertrain system from the bus body and frame at the rear mount side, as shown in Figure 6. Figure 7 shows the hammer impact at the left-front suspension excitation input point during FRF measurement. Figure 8 shows the amplitude and phase of FRFs from $X, Y$, and $Z$ DoFs at the left mount input side to the $Z$ DoF of response point (rear seat floor).

From the FRFs spectrum, it can be seen that the transmissibility amplitude and phase of different transfer paths at different frequencies are very different. In Figure 8(a), it can be found that the peak frequency of the three FRF spectra is all around $65 \mathrm{~Hz}$, and also, in Figure $8(\mathrm{~b})$, there is a phase sudden jump around $65 \mathrm{~Hz}$; therefore, it can be supposed that $65 \mathrm{~Hz}$ is one natural frequency of bus body and frame.

3.3. Path Contribution Analysis. After the first two steps illustrated in Section 3.2, all the interface forces can be identified by using the singular value decomposition; then, substituting the FRFs and the identified interface forces into equation (1), the vibration contribution of all transfer paths can be calculated. The obtained path contribution at the bus speed of $60 \mathrm{~km} / \mathrm{h}$ and $90 \mathrm{~km} / \mathrm{h}$ is analyzed below.

3.3.1. The Evaluation Method. The actual contribution of one transfer path to the interested point lies on both the amplitude of FRFs and interface forces and the phase; therefore, both the amplitude and phase should be taken into consideration to calculate the path contribution.

Figure 9 shows the schematic diagram of the phase and amplitude contribution of an example with four transfer paths. It can be clearly seen from the figure that path 1 and path4 aggravate vibration and need to be controlled, while path2 and path3 inhibit vibration, which is beneficial to reduce the vibration. 


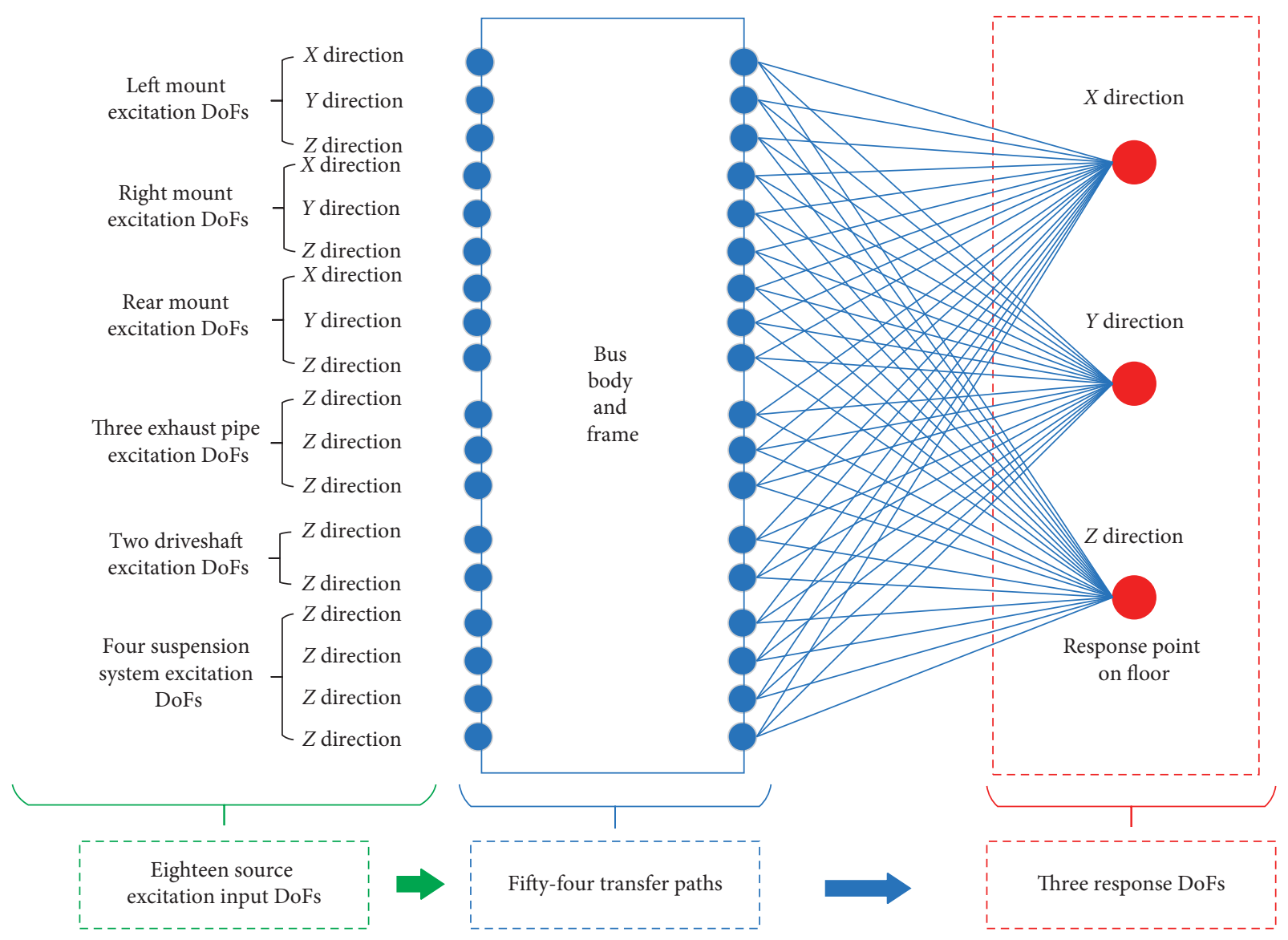

Figure 3: The established TPA model.

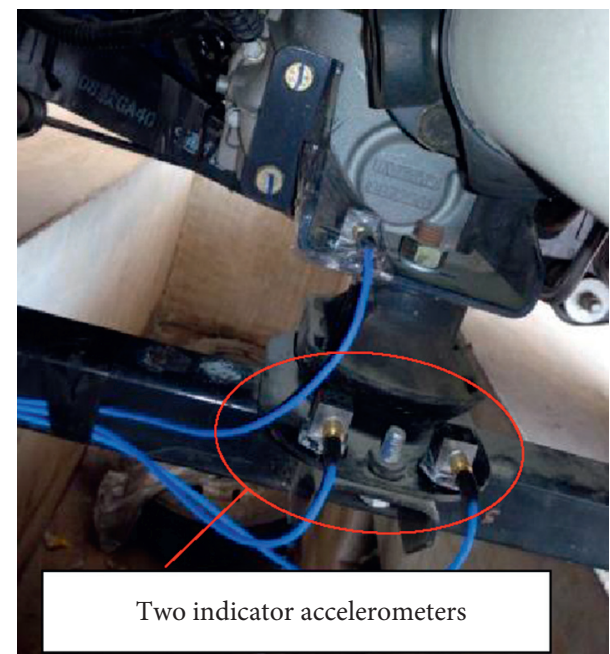

FIgURE 4: The two indicator accelerometers' placement near the passive side of rear mount.

At a certain frequency, we set the phase weighting coefficient $W_{i}$ of the $i^{\text {th }}$ transfer path as

$$
W_{i}=\cos \alpha_{i}
$$

where $i$ is the phase angle between the contribution vector of the transfer $i^{\text {th }}$ path and the total vibration vector (take the total vibration vector as the basis axis and counterclockwise as the positive direction).

When $-90^{\circ} \leq \alpha \leq 90^{\circ}$, the value of $W_{i}$ is positive, which means that this transfer path aggravates the vibration.

When $-90^{\circ} \leq \alpha<-90^{\circ}$ or $90^{\circ}<\alpha<180^{\circ}$, the value of $W_{i}$ is negative, which means that this transfer path weakens the vibration.

Taking both amplitude and phase into consideration, the overall contribution of the $i^{\text {th }}$ transfer path can be expressed as

$$
c_{i}=A_{i} W_{i},
$$

where $A_{i}$ is the contribution amplitude of the $i^{\text {th }}$ transfer path at a certain frequency and $c_{i}$ is the overall vibration contribution at this frequency.

Therefore, the total vibration contribution of the $i^{\text {th }}$ transfer path can be expressed as

$$
C_{i}=\frac{\sum_{n=1}^{N} c_{1}}{N},
$$

where $N$ is the peak number of the frequency spectrum and $C_{i}$ is the total contribution. 


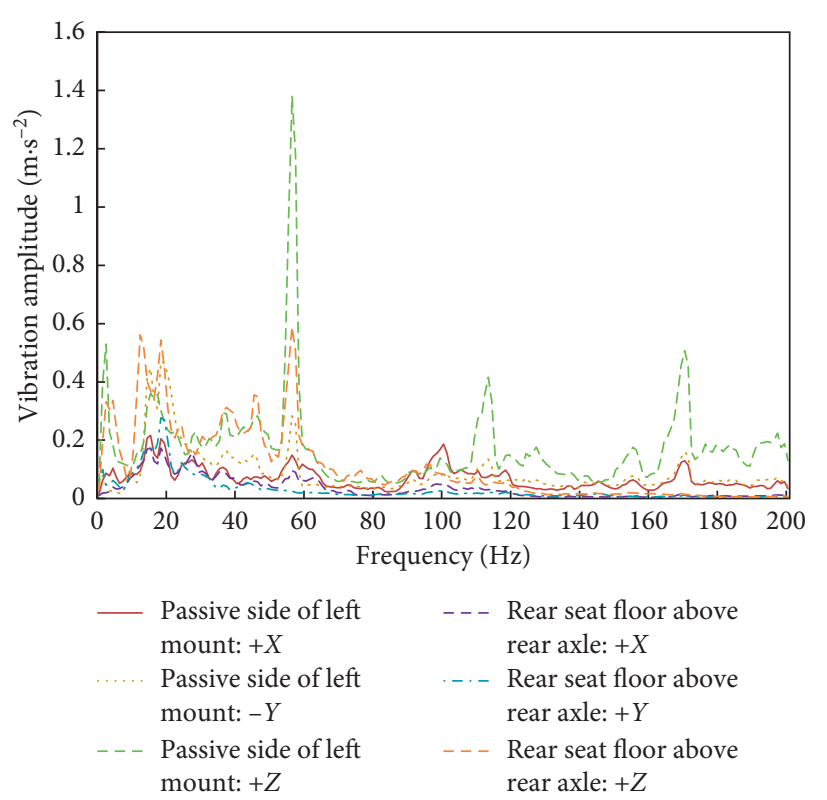

Figure 5: The vibration spectrum curves of response and some indicator DoFs.

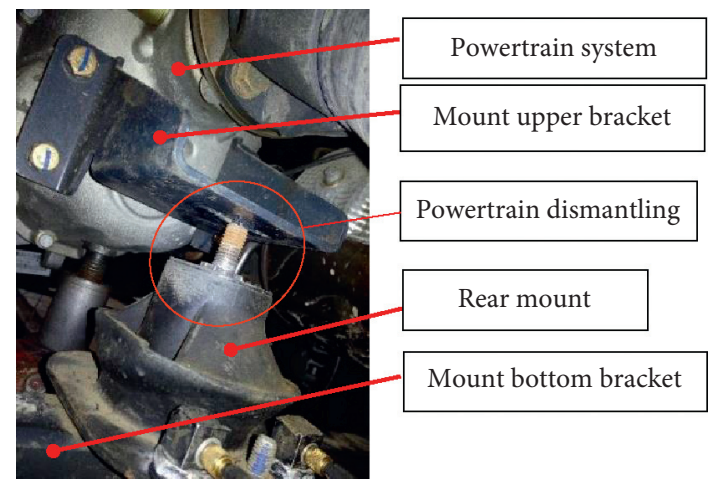

FIGURE 6: The dismantling of the powertrain system at rear mount.

The evaluation method here can be used in the following section to evaluate the vibration contribution of each path.

\subsubsection{Results of Path Contribution Analysis}

(1) Path Contribution Analysis of Bus Speed $60 \mathrm{~km} / \mathrm{h}$. The vibration spectrum of RSF at the bus speed of $60 \mathrm{~km} / \mathrm{h}$ is shown in Figure 10.

According to the evaluation method in Section 3.3.1, we calculate the total vibration contribution of all transfer paths of RSF at the bus speed of $60 \mathrm{~km} / \mathrm{h}$, and the results are shown in Figure 11.

It can be seen from Figure 11 that at the bus speed of $60 \mathrm{~km} / \mathrm{h}$, the vibration contribution of left-rear suspension $Z$ DoF and right-rear suspension $Z$ DoF to RSF is negative, of which the values are $-0.00014 \mathrm{~m} / \mathrm{s}^{2}$ and $-0.00279 \mathrm{~m} / \mathrm{s}^{2}$; it means that these two paths weanken the vibration. The vibration contributions of right mount DoFs, $Z$ DoF of second driveshaft support, left mount DoFs, and right-front

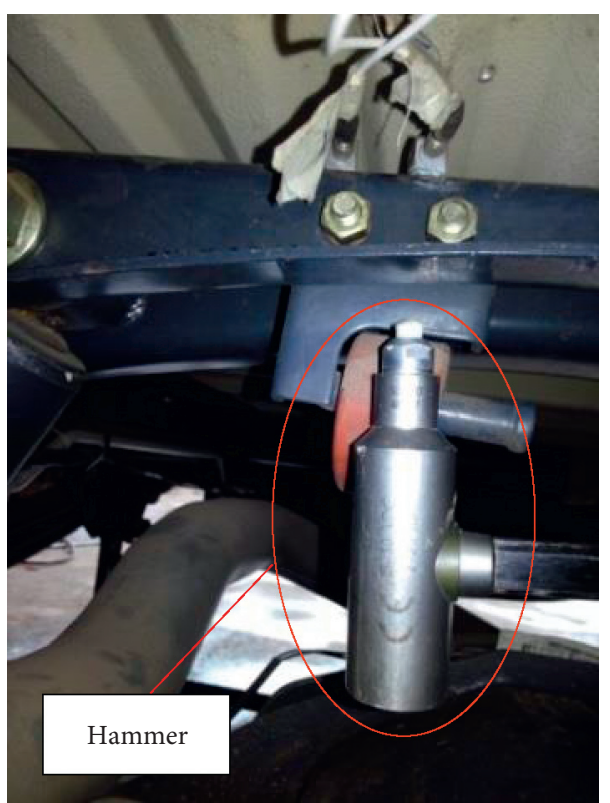

FIgURE 7: The hammer impact test of $Z$ direction at left-front suspension.

suspension $Z$ DoF to RSF are all positive, of which the values are $\quad 0.031615 \mathrm{~m} / \mathrm{s}^{2}, \quad 0.013276 \mathrm{~m} / \mathrm{s}^{2}, \quad 0.012835 \mathrm{~m} / \mathrm{s}^{2}$, and $0.012783 \mathrm{~m} / \mathrm{s}^{2}$, respectively; it means that these paths aggravate the vibration of RSF.

(2) Path Contribution Analysis of Bus Speed $90 \mathrm{~km} / \mathrm{h}$. The vibration frequency spectrum of RSF at the bus speed of $90 \mathrm{~km} / \mathrm{h}$ is shown in Figure 12.

The total vibration contribution of all transfer paths of RSF at the bus speed of $60 \mathrm{~km} / \mathrm{h}$ is calculated as that of $60 \mathrm{~km} / \mathrm{h}$; the results are shown in Figure 13.

It can be seen from Figure 13 that at the bus speed of $90 \mathrm{~km} / \mathrm{h}$, the total vibration contributions of the path of the left-front suspension system input DoF, three left mount input DoFs, left-rear suspension system input DoF, and right-rear suspension input $Z$ DoF to RSF $Z$ direction are all negative, of which the values are $-0.00666 \mathrm{~m} / \mathrm{s}^{2}$, $-0.006506 \mathrm{~m} / \mathrm{s}^{2},-0.005244 \mathrm{~m} / \mathrm{s}^{2}$, and $-0.0016624 \mathrm{~m} / \mathrm{s}^{2}$, respectively; it means that all the paths weaken the vibration of RSF. However, the vibration contributions of the path of second driveshaft input $Z$ DoF and three right mount input DoFs, and right-front suspension $Z$ DoF to $Z$ DoF response of RSF are all positive, of which the values are $0.054713 \mathrm{~m} / \mathrm{s}^{2}, 0.047155 \mathrm{~m} / \mathrm{s}^{2}$, and $0.0062955 \mathrm{~m} / \mathrm{s}^{2}$, respectively; it means that these paths will aggravate the vibration of RSF.

Therefore, the conclusion can be obtained based on the above analysis as follows:

(a) The vibration contributions of the path of second driveshaft input $Z$ DoF, right mount input DoFs, and right-front suspension system input $Z$ DoF to both the bus speed of $60 \mathrm{~km} / \mathrm{h}$ and $90 \mathrm{~km} / \mathrm{h}$ are positive and obviously higher than other paths; therefore, these paths need to be controlled firstly. 


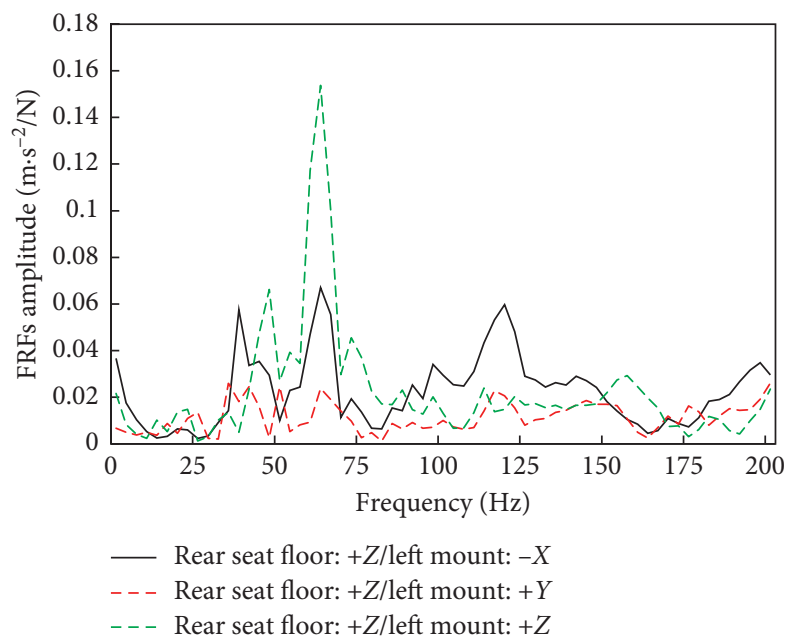

(a)

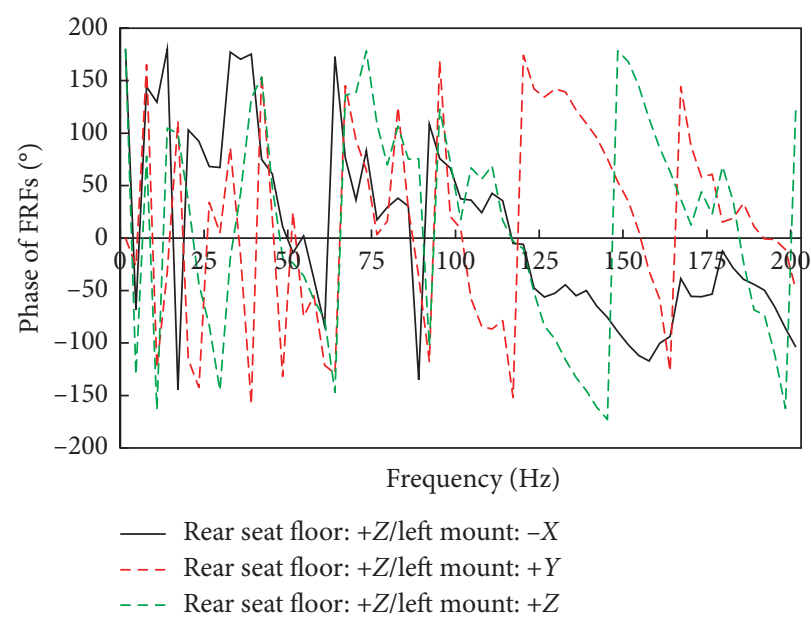

(b)

FIgURE 8: The amplitude/phase spectrum of FRFs from left mount input DoFs to response $Z$ DoF. (a) The amplitude of FRFs. (b) The phase of FRFs.

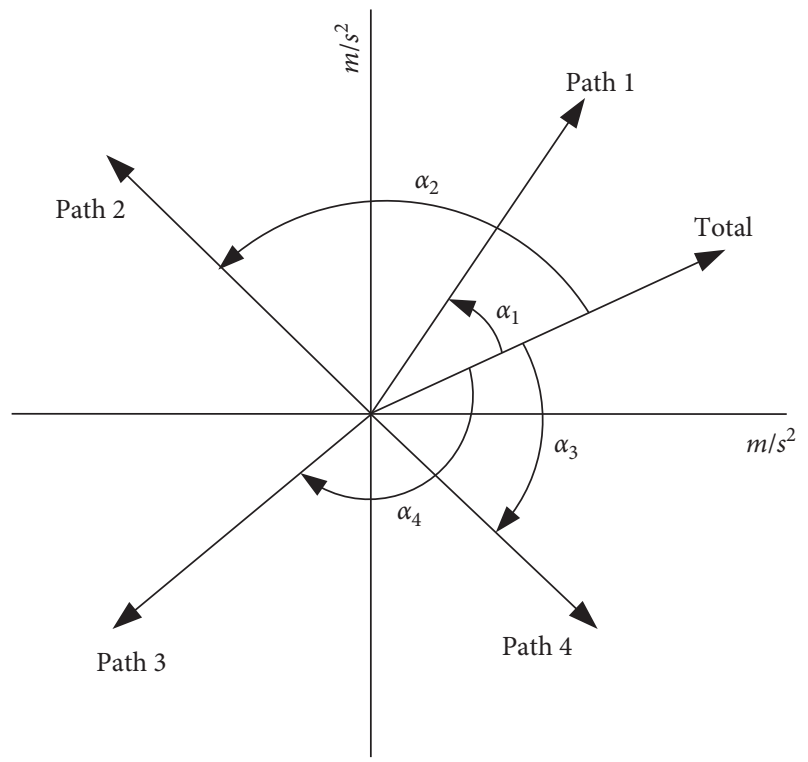

FIGURE 9: The diagrammatic sketch of amplitude and phase contribution.

(b) Although the vibration contribution of the path of three left mount input DoFs to RSF at the bus speed of $90 \mathrm{~km} / \mathrm{h}$ is negative, of which the value is $-0.006506 \mathrm{~m} / \mathrm{s}^{2}$, at the bus speed of $60 \mathrm{~km} / \mathrm{h}$, it is positive, of which the amplitude is higher than the former; therefore, this path needs to be controlled balancedly to some extent.

(c) The vibration contribution values are very small for the path of first driveshaft $\mathrm{Z} \mathrm{DoF}$, leftfront suspension $\mathrm{Z}$ DoF, leftrear suspension $\mathrm{Z}$ DoF, and rightrear suspension $Z$ DoF to RSF at the bus speed of both $60 \mathrm{~km} / \mathrm{h}$ and $90 \mathrm{~km} / \mathrm{h}$; therefore, these paths are not the dominant paths.

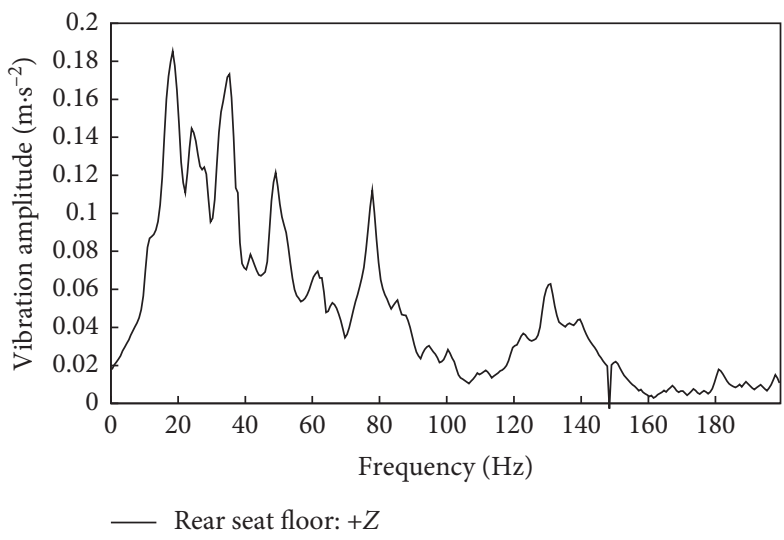

FIGURE 10: The vibration of rear seat floor at the bus speed of $60 \mathrm{~km} / \mathrm{h}$.

In conclusion, the paths which need to be controlled are the paths of second driveshaft input $Z \mathrm{DoF}$, three right mount input DoFs, and right-front suspension input $Z$ DoF; also, the paths of three left mount input DoFs need to be controlled to some extent.

\section{Rubber Stiffness Optimization for Vibration Reduction}

To solve the vibration problem of the studied light bus, as analyzed in the above section, the dominant paths should be improved. However, the peak frequencies of vibration response are not always the same as the natural frequencies of PMS. The peak frequencies of response lie on the amplitude and phase spectrum of both vehicle body FRFs and excitation forces of the powertrain system. According to transfer path concept, the vibration response can be calculated by multiplying the in situ original excitation force of engine and the force transmissibility. It would cost much effort to 


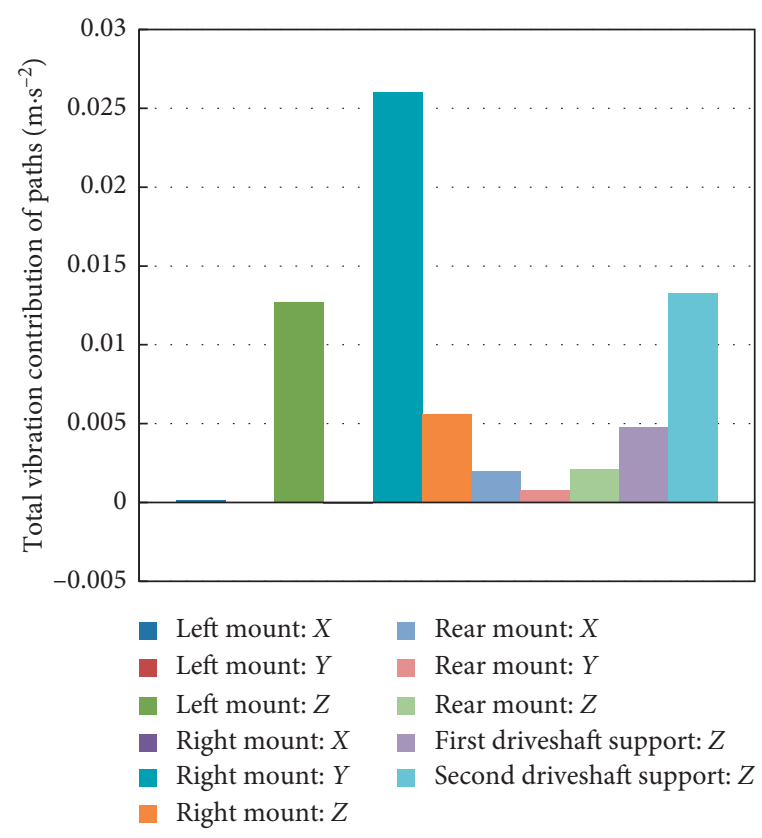

(a)

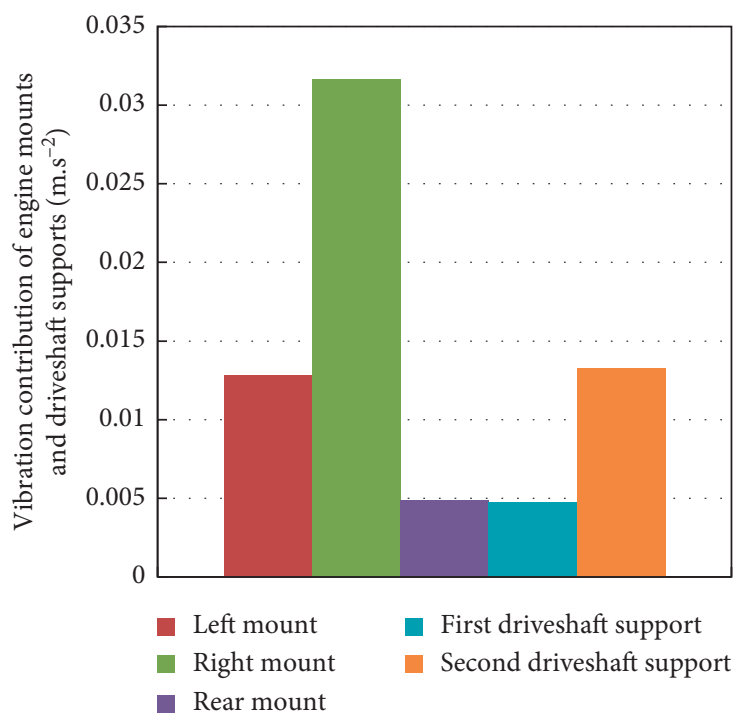

(b)

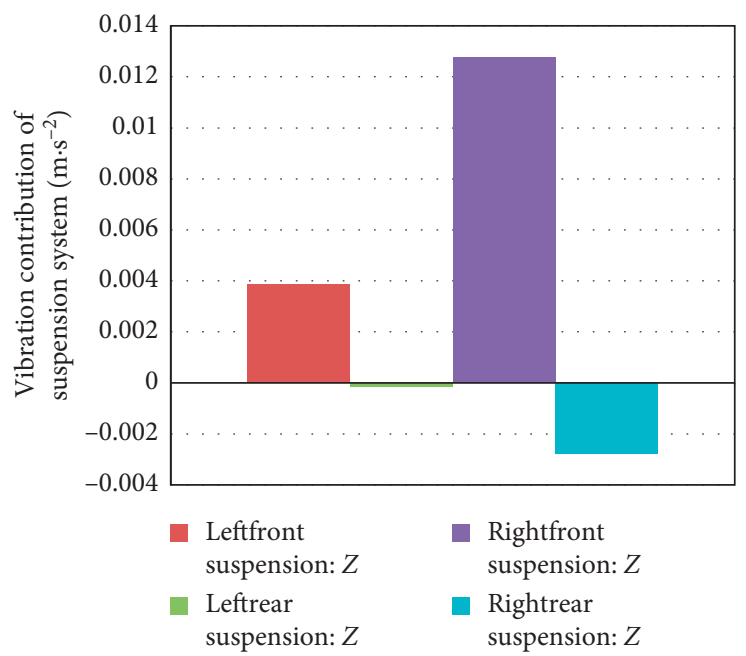

(c)

FIGURE 11: The total vibration contribution of all paths to RSF at the bus speed of $60 \mathrm{~km} / \mathrm{h}$. (a) The total vibration contribution of paths of nine engine input DoFs and two driveshaft input DoFs (individual). (b) The total vibration contribution of paths of nine engine input DoFs and two driveshaft input DoFs (in group). (c) The total vibration contribution of transfer paths of four suspension system input DoFs.

redesign the engine and vehicle body for lower excitation forces and better FRF transmissibility property, respectively. Therefore, reducing the force transmissibility of the rubber isolation system is a highly efficient and less cost method. Ignoring the vehicle body resilience and that each DoF is mutually independent, the force transmissibility depends on the damping coefficient and stiffness of PMS if other parameters are unchanged. However, generally, the six DoFs of the powertrain mount system (PMS) are coupled with each other, which widens the frequency bandwidth of vibration resonance and also leads to serious vibration of all six DoFs of PMS once one DoF resonates. Therefore, by vibration decoupling optimization, energy coupling between six DoFs of PMS can be reduced significantly.
There are three methods to decouple the vibration coupling between DoFs, i.e., torque axis method, impact center theory, and energy decoupling method. The former two methods are only used in the main inertial axis coordinate system, if the powertrain system is asymmetric and the deviation angle of the main inertia shaft relative to the crankshaft is large, it is not applicable for the former two methods. The energy decoupling method is universal and limited to the engine type and layout. Therefore, the energy decoupling method is usually selected to be improved.

In this paper, the energy decoupling method, not the force transmissibility, is selected as one of the optimization objective functions. In next several sections, the 


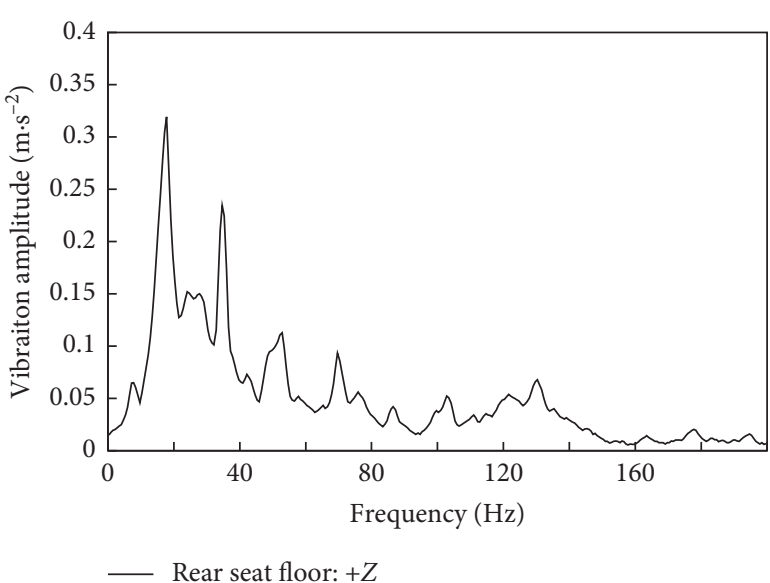

FIGURE 12: Vibration response of $Z$ DoF at RSF at the bus speed of $90 \mathrm{~km} / \mathrm{h}$.

rubber stiffness optimization by energy decoupling rate based on the path contribution analysis of matrix inversion TPA is elaborated, of which the workflow is shown in Figure 14.

4.1. Energy Decoupling Theory Derivation. For a multi-DoF vibration system (such as the powertrain mount system in this paper), the total kinetic energy of the $i^{\text {th }}$ mode can be expressed as

$$
E_{\max }^{i}=\frac{1}{2} \dot{Q}_{\max }^{T} M \dot{Q}_{\max }=\frac{1}{2} \omega_{1}^{2} \sum_{k=1}^{6} \sum_{l=1}^{6} M_{k l}\left(\varphi_{i}\right)_{k}\left(\varphi_{i}\right)_{l}=\sum_{k=1}^{6} E_{k}^{i},
$$

where $\alpha_{i}$ is the natural frequency of the $i^{\text {th }}$ mode; $M_{k l}$ is the element of the $k^{\text {th }}$ row and $i^{\text {th }}$ column of the system mass matrix; $\left(\varphi_{i}\right)_{k}$ and $\left(\varphi_{i}\right)_{l}$ are the $k^{\text {th }}$ and $l^{\text {th }}$ elements of the $i^{\text {th }}$ mode vector, respectively; $i, k$ and $l=1,2, \ldots, 6$.

The kinetic energy of the $k^{\text {th }}$ generalized coordinate in the $i^{\text {th }}$ mode vector is

$$
E_{k}^{i}=\frac{1}{2} \omega_{1}^{2} \sum_{k=1}^{6} \sum_{l=1}^{6} M_{k l}\left(\varphi_{i}\right)_{k}\left(\varphi_{i}\right)_{l}
$$

Combining equations (13) with (14), the total vibration kinetic energy of the $i^{\text {th }}$ mode is obtained by superposing the six-component kinetic energies $E_{k}^{i}$ $(k=1,2, \ldots, 6)$. According to the energy conservation law, if the kinetic energy on one direction of $i^{\text {th }}$ mode increases, the kinetic energy in other directions would decrease.

Therefore, the ratio of kinetic energy in the $k^{\text {th }}$ direction to the total kinetic energy of the $i^{\text {th }}$ mode can be expressed as

$$
T_{k i}=\frac{\sum_{l=1}^{6} M_{k l}\left(\varphi_{i}\right)_{l}\left(\varphi_{i}\right)_{k}}{\sum_{k=1}^{6} \sum_{l=1}^{6} M_{k l}\left(\varphi_{i}\right)_{k}\left(\varphi_{i}\right)_{l}}
$$

where $T_{k i}$ is the EDR of the $k^{\text {th }}$ direction of the $i^{\text {th }}$ mode. When the EDR value is $100 \%$, it means the PMS is completely decoupled in the $i^{\text {th }}$ mode; namely, vibration occurs only on the $k^{\text {th }}$ direction. Practically, it is difficult to decouple the PMS completely; therefore, in this research, the EDR of the direction of the dominant path is required to be greater than $90 \%$, in other directions greater than $80 \%$.

4.2. The Optimization Parameter Design. According to the path contribution analysis results in Section 3, the stiffness of left or right mount, second driveshaft support, and $Z$ direction of right-front suspension rubber can be selected as the optimization variables. The next sections illustrate the workflow of stiffness optimization to reduce the vibration at the bus speed of $60 \mathrm{~km} / \mathrm{h}$.

4.2.1. Selecting Design Variables. Owning to the left mount and right mount are the same, the optimization design variables can be selected to be the stiffness of the $X$ direction, $Y$ direction, and $Z$ direction of the two mounts, $Z$ direction of second driveshaft support, and $Z$ direction of right-front suspension rubber.

\subsubsection{Constraint Conditions}

(1) Stiffness Constraint Conditions. Usually for rubber component, it exists $10 \% \sim 20 \%$ mismatching tolerance. Therefore, the variation of the stiffness of the five variables is confined to the range of $\pm 20 \%$ around the original value.

(2) Natural Frequency Constraints. The natural frequency and EDR of PMS before optimization are shown in Table 1.

Usually, to increase the life span of mount elements, the natural frequencies of PMS need to be higher than $5 \mathrm{~Hz}$. It can be seen from Table 1 that the natural frequency of each DoF meets the requirement, but the natural frequencies of translational $Z$ DoF and rotational $Z$ DoF are more or less the same with that of rotational $X$ DoF and $Y$ DoF, respectively; therefore, the vibration resonance happens with high possibility. The energy decoupling rate of translational $Y$ and $Z$ and rotational $Y$ and $Z$ is very small, of which the values are $65.74 \%$, $59.27 \%, 66.83 \%$, and $56.12 \%$, respectively; especially, the energy coupling between translational $Z$ DoF and rotational $Y$ or rotational $Z$ is very serious; commonly, the EDR of one DoF of the mount system should be greater than $80 \%$, and the natural frequency of the mount system should be allocated reasonably; also, the natural frequency interval should be about $1 \mathrm{~Hz}$.

\subsubsection{Determining Objective Function}

(1) First Objective Function. To improve the floor vibration of a light bus, especially the vibration of RSF above rear axle, the first objective function can be selected to minimize the $Z$ direction acceleration value of the response point on the floor around rear seats above rear axle, namely, 


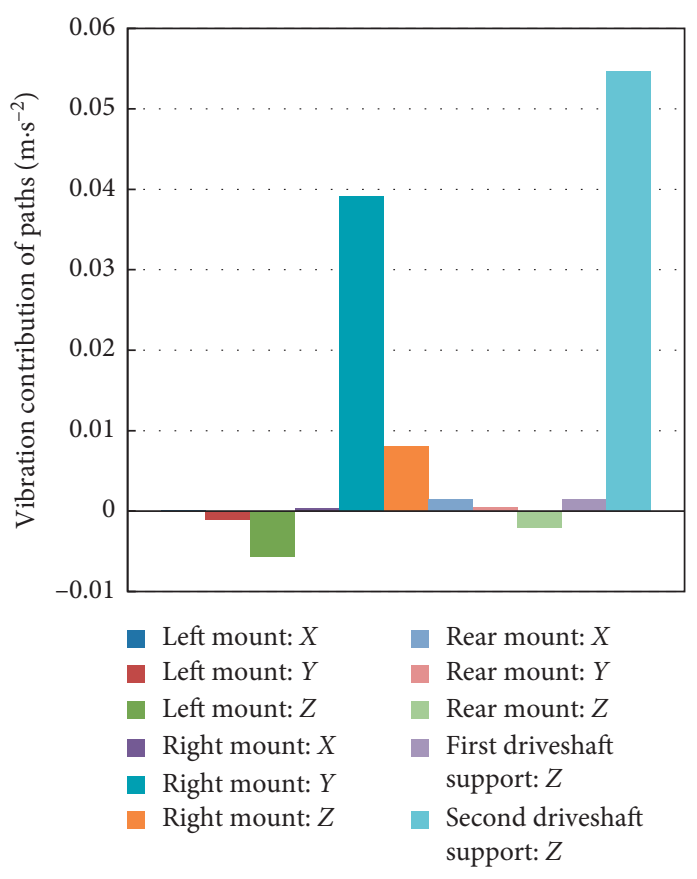

(a)

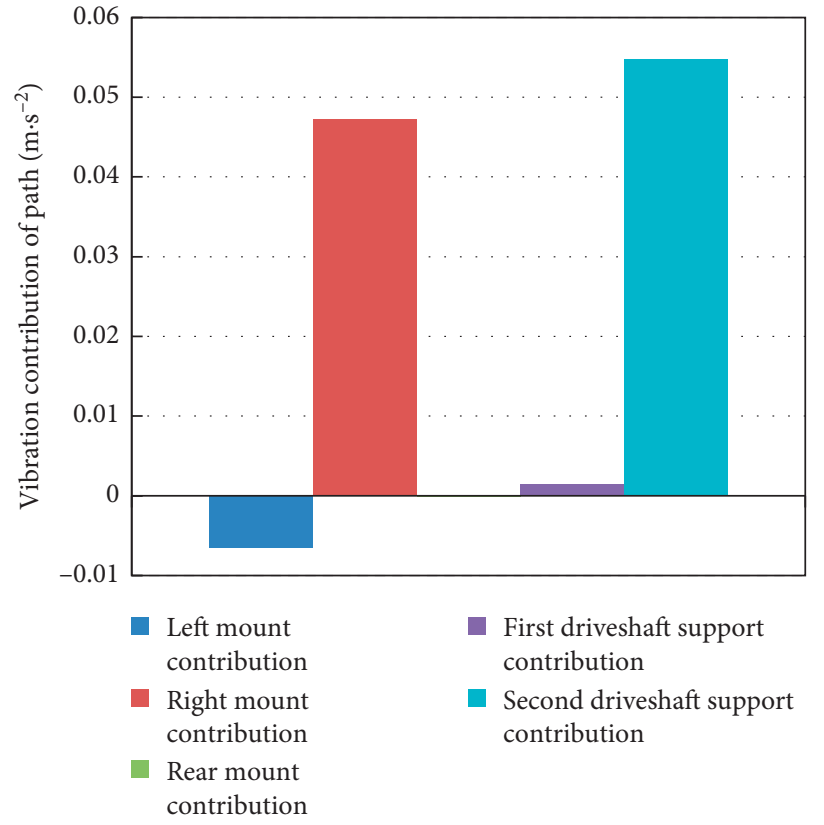

(b)

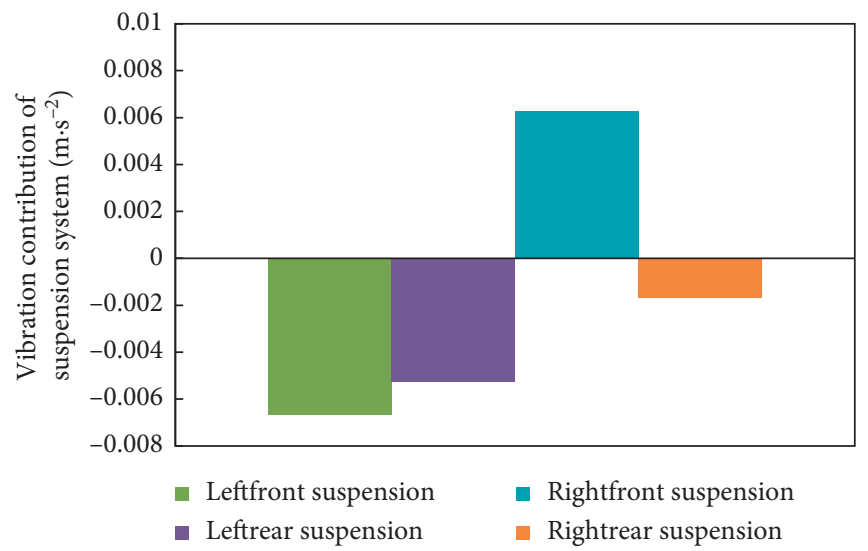

(c)

FIGURE 13: The total vibration contribution of all paths to RSF at the bus speed of $90 \mathrm{~km} / \mathrm{h}$. (a) The total vibration contribution of paths of nine engine input DoFs and two driveshaft input DoFs (individual). (b) The total vibration contribution of paths of nine engine input DoFs and two driveshaft input DoFs (in group). (c) The total vibration contribution of transfer paths of four suspension system input DoFs.

$$
F_{1}=\min \left(z_{1}\right)
$$

(2) Second Objective Function. Also, the energy decoupling rate of PMS should be taken into consideration; therefore, the objective function for energy decoupling rate is

$$
F_{2}=\sum_{i=1}^{6} w_{i}\left(100-\mathrm{Vep}_{i}\right),
$$

where $E_{k}^{i}=1 / 2 \omega_{i}^{2} \sum_{l=1}^{6} M_{k l}\left(\varphi_{i}\right)_{k}\left(\varphi_{i}\right)_{l}$ denotes the $i^{\text {th }}$ mode of PMS; $E_{k}^{i}$ is the weight coefficient of the $i^{\text {th }}$ mode; Vep $i$ is energy percentage of the DoF with principle vibration energy of the $i^{\text {th }}$ natural frequency.

The overall objective function is constructed by combining the first objective function with the second objective function by different weighting coefficients. Because the effect degree of the two subobjective functions is different, also both of them need to be taken into consideration; the two objective functions should be weighted by different coefficients. If the first objective function is only taken into consideration, the optimization would yield bad energy decoupling rate; conversely, if 


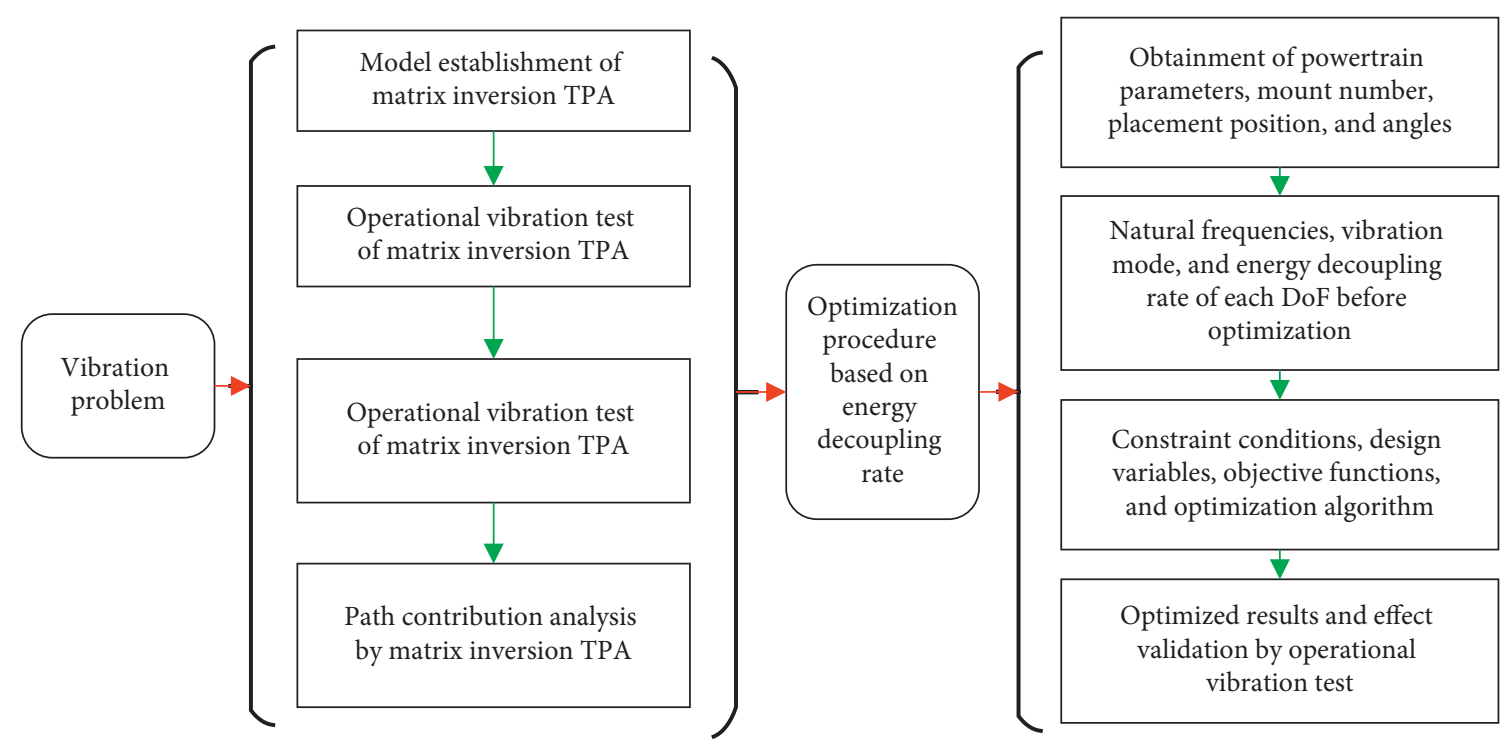

FIGURE 14: The workflow flowchart in this paper.

TABLE 1: The natural frequency and energy decoupling rate of PMS before optimization.

\begin{tabular}{|c|c|c|c|c|c|c|c|}
\hline \multicolumn{2}{|c|}{$\begin{array}{l}\text { The DoF with principle } \\
\text { energy }\end{array}$} & Translational $X$ & Translational $Y$ & Translational $Z$ & Rotational $X$ & Rotational $Y$ & Rotational $Z$ \\
\hline \multicolumn{2}{|c|}{ Natural frequency $(\mathrm{Hz})$} & 5.81 & 7.69 & 9.35 & 13.12 & 13.22 & 9.08 \\
\hline \multirow{6}{*}{ EDR } & Translational $X$ & 88.24 & 0.03 & 5.43 & 0.48 & 3.47 & 2.34 \\
\hline & Translational $Y$ & 0.01 & 65.74 & 7.56 & 7.47 & 0.59 & 18.64 \\
\hline & Translational $Z$ & 2.61 & 0.07 & 59.27 & 0.51 & 20.81 & 16.73 \\
\hline & Rotational $X$ & 0.02 & 8.01 & 2.27 & 79.34 & 6.71 & 3.66 \\
\hline & Rotational $Y$ & 8.96 & 0.04 & 13.21 & 8.53 & 66.83 & 2.53 \\
\hline & Rotational $Z$ & 0.15 & 26.17 & 12.27 & 3.70 & 1.57 & 56.12 \\
\hline
\end{tabular}

only the second objective function is considered, the optimization results would not maximize the first objective function. Therefore, the weight coefficients of first objective function and second objective function can be set as 0.3 and 0.7 , respectively; therefore, the overall objective function is

$$
F=0.3 \times F_{1}+0.7 \times F_{2}=0.3 \times \min \left(z_{1}\right)+0.7 \times\left(\sum_{\mathrm{l}=1}^{6} w_{i}\left(100-\mathrm{Vep}_{i}\right)\right)
$$

Some mathematical relationship exists between the design variables and vibration acceleration, we can use the quadratic regression equation to express the relationship, and the genetic algorithm is adopted as the optimization algorithm.

\subsection{The Optimization Results}

4.3.1. The Results of Stiffness Optimization. According to aforementioned optimization workflow, the objective function at bus speed of $60 \mathrm{~km} / \mathrm{h}$ and $90 \mathrm{~km} / \mathrm{h}$ is optimized in Matlab, and the results of optimized stiffness are shown in Table 2 .
Averaging the optimized results of both two bus speeds in Table 2, the final optimized stiffness is obtained, as shown in Table 3.

4.3.2. Energy Decoupling Rate after Optimization. After optimization, the EDR of PMS is calculated, of which the results are shown in Table 4.

It can be seen from Table 4 that the natural frequency intervals (except for the natural frequency interval between translational $Z$ and rotational $Z$ DoFs) basically meet the requirements. The energy decoupling rate of translational $Y$ DoF, translational $Z$ DoF, rotational $Y$ DoF, and rotational $Z$ DoF is improved from $65.74 \%$, $59.27 \%, 66.83 \%$, and $56.12 \%$ to $78.88 \%, 72.15 \%, 77.87 \%$, 
TABLe 2: The results of optimized PMS at the bus speed of $60 \mathrm{~km} / \mathrm{h}$ and $90 \mathrm{~km} / \mathrm{h}$ (unit: N/mm).

\begin{tabular}{lccccc}
\hline $\begin{array}{l}\text { Design variable } \\
\text { bus speed }\end{array}$ & $\begin{array}{c}\text { Stiffness of } X \\
\text { direction of front } \\
\text { mount }\left(x_{1}\right)\end{array}$ & $\begin{array}{c}\text { Stiffness of } Y \\
\text { direction of front } \\
\text { mount }\left(x_{2}\right)\end{array}$ & $\begin{array}{c}\text { Stiffness of } Z \\
\text { direction of front } \\
\text { mount }\left(x_{3}\right)\end{array}$ & $\begin{array}{c}\text { Stiffness of second } \\
\text { driveshaft } Z \text { direction } \\
\left(x_{4}\right)\end{array}$ & $\begin{array}{c}Z \text { direction stiffness of } \\
\text { right-front suspension } \\
\text { rubber }\left(x_{5}\right)\end{array}$ \\
\hline $60 \mathrm{~km} / \mathrm{h}$ & 128.2 & 345 & 552.4 & 89 & 1224.2 \\
\hline $90 \mathrm{~km} / \mathrm{h}$ & 100.2 & 345 & 552.4 & 124 & 1225.2 \\
\hline
\end{tabular}

TABLE 3: The final optimized rubber stiffness (unit: $\mathrm{N} / \mathrm{mm}$ ).

\begin{tabular}{lccccc}
\hline Design variables & $\begin{array}{l}X \text { direction stiffness } \\
\text { of front mount }\left(x_{1}\right)\end{array}$ & $\begin{array}{l}Y \text { direction stiffness } \\
\text { of front mount }\left(x_{2}\right)\end{array}$ & $\begin{array}{l}Z \text { direction stiffness front mount }\left(x_{3}\right) \\
\text { of }\end{array}$ & $\begin{array}{c}Z \text { direction stiffness of } \\
\text { second driveshaft } \\
\text { support }\left(x_{4}\right)\end{array}$ & $\begin{array}{c}Z \text { direction stiffness of } \\
\text { right-front suspension } \\
\text { rubber }\left(x_{5}\right)\end{array}$ \\
\hline Stiffness value & 114 & 352 & 552 & 107 & 1225 \\
\hline
\end{tabular}

TABLE 4: The natural frequencies and energy decoupling rate of PMS after optimization.

\begin{tabular}{|c|c|c|c|c|c|c|c|}
\hline \multicolumn{2}{|c|}{ DoF with principal vibration energy } & \multirow{2}{*}{$\begin{array}{c}\text { Translational } X \\
5.68\end{array}$} & \multirow{2}{*}{$\begin{array}{c}\text { Translational } Y \\
7.20\end{array}$} & \multirow{2}{*}{$\begin{array}{c}\text { Translational } Z \\
8.25 \\
\end{array}$} & \multirow{2}{*}{$\begin{array}{c}\text { Rotational } X \\
13.52 \\
\end{array}$} & \multirow{2}{*}{$\begin{array}{c}\text { Rotational } Y \\
13.03 \\
\end{array}$} & \multirow{2}{*}{$\begin{array}{c}\text { Rotational } Z \\
9.07 \\
\end{array}$} \\
\hline Natural frequency $(\mathrm{Hz})$ & & & & & & & \\
\hline \multirow{6}{*}{$\begin{array}{l}\text { Energy decoupling } \\
\text { distribution }\end{array}$} & Translational $X$ & 85.40 & 0.02 & 9.40 & 0.01 & 4.02 & 0.38 \\
\hline & Translational $Y$ & 0.00 & 78.88 & 0.00 & 13.52 & 0.00 & 7.13 \\
\hline & Translational $Z$ & 4.38 & 0.29 & 72.15 & 0.20 & 18.04 & 5.75 \\
\hline & Rotational $X$ & 0.07 & 14.30 & 1.42 & 84.56 & 0.02 & 0.01 \\
\hline & Rotational $Y$ & 9.82 & 0.36 & 10.50 & 0.08 & 77.87 & 1.50 \\
\hline & Rotational $Z$ & 0.33 & 6.15 & 6.53 & 1.63 & 0.05 & 85.23 \\
\hline
\end{tabular}

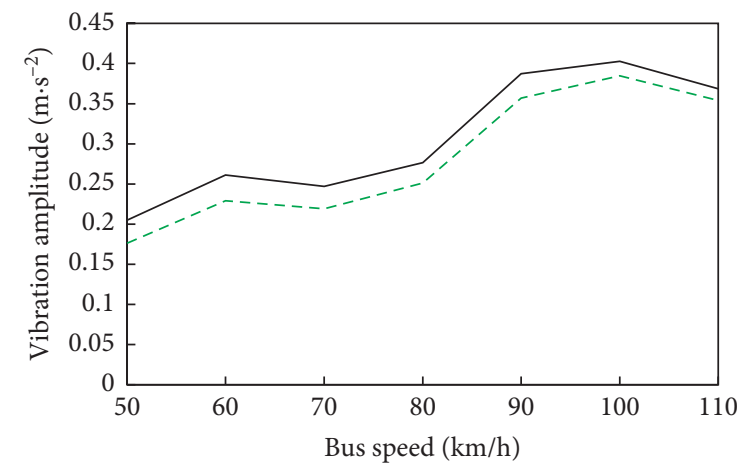

- $X$ direction vibration before optimization

-- $X$ direction vibration after optimization

(a)

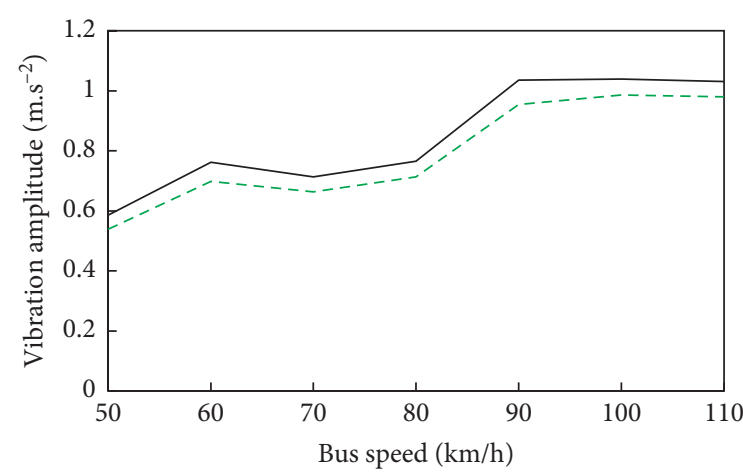

- $Z$ direction vibration before optimization

- - $Z$ direction vibration after optimization

(c)

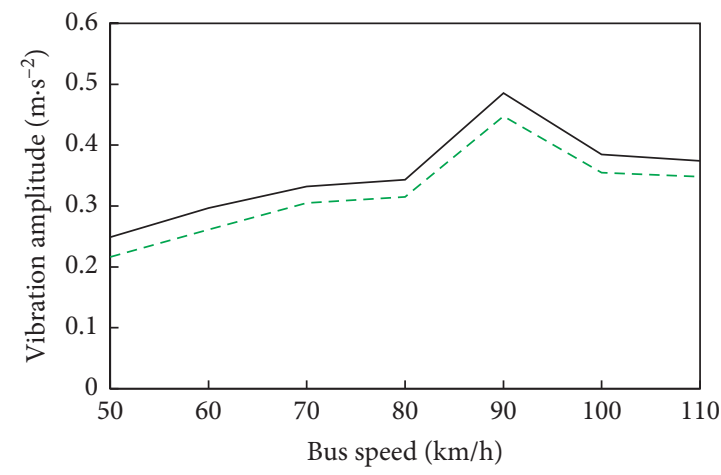

- $Y$ direction vibration before optimization

-- $Y$ direction vibration after optimization

(b)

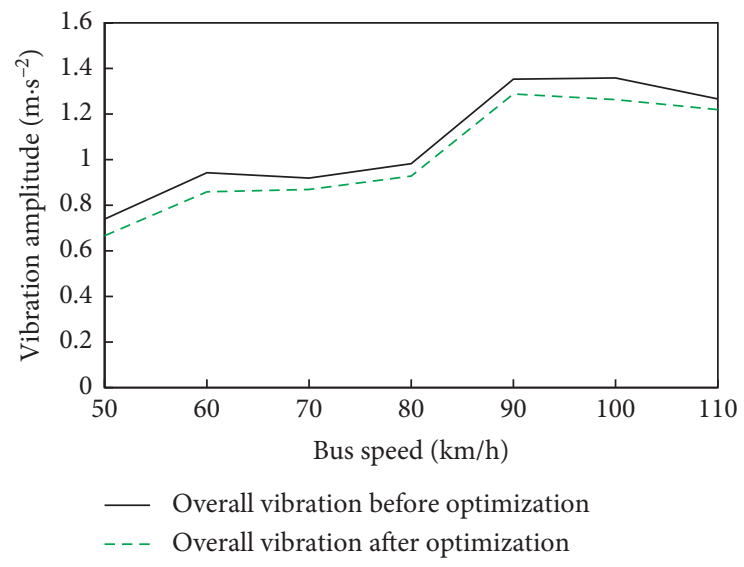

(d)

FIGURE 15: Vibration level comparison of RSF between preoptimization and postoptimization. (a) Weighted acceleration RMS of $X$ DoF. (b) Weighted acceleration RMS of $Y$ DoF. (c) Weighted acceleration RMS of $Z$ DoF. (d) Overall weighted acceleration RMS. 
and $85.23 \%$, respectively. It indicates that the isolation performance of the mount system is improved after optimization. Please note that the natural frequencies of optimized PMS are all lower than $20 \mathrm{~Hz}$. To avoid the vibration resonance of PMS, according to vibration isolation theory, the natural frequencies of PMS (as shown in Table 4) are required to be designed lower than the $1 / \sqrt{2}$ times (i.e., $18.86 \mathrm{~Hz}$ ) the frequency of second-order engine excitation force under idling condition(the idling speed is $800 \mathrm{rpm}$, and the idling excitation frequency is $26.67 \mathrm{~Hz}$ ). Therefore, the bandwidth frequency of problem is inconsistent with the natural frequencies optimized of PMS. And the optimized natural frequencies meet the requirement of vibration isolation.

\section{Optimization Effect Validation}

The operational vibration test of the light bus with the optimization rubbers installed is carried out to validate the optimization effect at different bus speeds, by which the three-direction vibration and overall weighted acceleration RMS level of RSF are obtained. Comparing the optimized vibration level with that before optimization, the comparison results are obtained, as shown in Figure 15.

It can be seen from Figure 15 that the acceleration RMS of $X$ DoF, $Y$ DoF, and $Z$ DoF and overall weighted vibration of RSF are improved significantly after optimization. Taken the bus speed $60 \mathrm{~km} / \mathrm{h}$ as an example, the acceleration RMS of $X \mathrm{DoF}, Y \mathrm{DoF}$, and $Z \mathrm{DoF}$ are reduced from $0.261 \mathrm{~m} / \mathrm{s}^{2}$, $0.297 \mathrm{~m} / \mathrm{s}^{2}$, and $0.762 \mathrm{~m} / \mathrm{s}^{2}$ to $0.229 \mathrm{~m} / \mathrm{s}^{2}, 0.261 \mathrm{~m} / \mathrm{s}^{2}$, and $0.698 \mathrm{~m} / \mathrm{s}^{2}$, respectively, and the overall acceleration RMS is reduced by $8.8 \%$, from $0.942 \mathrm{~m} / \mathrm{s}^{2}$ to $0.859 \mathrm{~m} / \mathrm{s}^{2}$. The test results show that the vibration level of the light bus at the bus speed of $60 \mathrm{~km} / \mathrm{h}$ and $90 \mathrm{~km} / \mathrm{h}$ is improved markedly, which means that the floor vibration problem is solved.

\section{Conclusions}

TPA is one of the effective tools to solve practical NVH problems. To solve the severe vibration problem of the RSF of a light bus, the research in this paper presents the combination of the experiment-based matrix inversion TPA for the identification of the dominant transfer paths with the EDR optimization procedure. The results of this study indicate that rubber stiffness optimization based on the paths contribution by MITPA can significantly reduce the RSF vibration. The main conclusions obtained are as follows:

(a) The matrix inversion TPA is derived by the dynamic substructure theory. The singular value decomposition rejection method is applied, which serves as a good method to enhance the measurement error amplification caused by ill-conditioning of FRF matrix inversion.

(b) To solve the problematic floor vibration of a light bus, especially at the speed of $60 \mathrm{~km} / \mathrm{h}$ and $90 \mathrm{~km} / \mathrm{h}$, the TPA analysis model establishment, operational vibration test, and FRF measurement by the hammer impact test are carried out. By implementing the matrix inversion TPA analysis to analyze the mentioned problem, the dominant paths are identified.

(c) Based on path contribution results, the energy decoupling rate optimization method is selected to improve the isolation performance of PMS. The optimized results show that the energy decoupling rate of postoptimized PMS is better that of preoptimized. The operational vibration test results after optimization validates that the vibration level of RSF is improved comparing with the vibration level before optimization. It indicates that the investigated combination method is effective to improve the vibration problem in engineering.

In this paper, the combination of experimental TPA for the dominant path identification with the optimization procedure solves the vibration problem accurately and effectively. However, there are some limitations in this research. On one hand, application of other TPA methods can also be further studied to analyze the vibration problem of RSF in this paper, such as operational TPA (OTPA) and OPAX; on the other hand, in the optimization procedure, the multiobjective function optimization method deserves to be investigated, which may obtain a better optimization result. Also some optimization algorithms can be further studied, such as the NAGA-II multiobjective genetic algorithm, or combining the genetic algorithm with the sequential quadratic programming (SQP) method.

At the same time, although the vibration level of the specific bus speed of $60 \mathrm{~km} / \mathrm{g}$ and $90 \mathrm{~km} / \mathrm{h}$ is reduced by mount stiffness optimization based on the path contribution analysis of matrix inversion TPA accurately, the cost and time consumption is high because the operational vibration test is required after optimization. It is a disadvantage for the forward calculation of vibration prediction and NVH design. The dynamic substructure theory (such as frequency-based substructuring, FBS) can be used to further predict the FRFs of transfer paths by simulation after each optimization or design cycle, which will accelerate the validation procedure and NVH design of a light bus.

\section{Data Availability}

The data used to support the findings of this study are available from the first author upon request.

\section{Conflicts of Interest}

The authors declare no conflicts of interest regarding the publication of this article.

\section{Acknowledgments}

This research work was partly supported by the National Key R\&D Program of China (project no. 2018YFB0106203). 


\section{References}

[1] S. R. Mohite, V. B. Bijwe, S. Deysarkar, and S. Chittick, "Application of flexible multi body dynamics (MBD) and finite element analysis (FEA) for powertrain induced $\mathrm{NVH}$ development of a vehicle," SAE Technical Papers, 2011.

[2] A. Acri, G. Offner, E. Nijman, and J. Rejlek, "Substructuring of multibody systems for numerical transfer path analysis in internal combustion engines," Mechanical Systems and Signal Processing, vol. 79, pp. 254-270, 2016.

[3] C. J. Cameron, P. Wennhage, and P. Göransson, "Prediction of NVH behavior of trimmed body components in the frequency range $100-500 \mathrm{~Hz}$," Applied Acoustics, vol. 71, no. 8, pp. 708-721, 2010.

[4] M. Antonietta Panza, "A review of experimental techniques for NVH analysis on a commercial vehicle," Energy Procedia, vol. 82, pp. 1017-1023, 2015.

[5] B. Sakhaei and M. Durali, "Vibration transfer path analysis and path ranking for NVH optimization of a vehicle interior," Shock and Vibration, vol. 2014, Article ID 697450, 5 pages, 2014.

[6] J. Tatlow and M. Ballatore, "Road noise input identification for vehicle interior noise by multi-reference transfer path analysis," Procedia Engineering, vol. 199, pp. 3296-3301, 2017.

[7] N. Falasifah and D. Arifianto, "Vibration characteristics of a car using transfer path analysis," The Journal of the Acoustical Society of America, vol. 146, no. 4, p. 2881, 2019.

[8] Z. Fang, H. Zhou, and E. Wang, "Matrix inversion method for load identification in transfer paths analysis," Lecture Notes in Electrical Engineering, vol. 141, no. 1, pp. 517-524, 2012.

[9] M. Van Der Seijs, E. Pasma, D. Klerk, and D. J. Rixen, “A comparison of two component TPA approaches for steering gear noise prediction," in Dynamics of Coupled Structures, vol. 4, pp. 71-79, Springer International Publishing, Berlin, Germany, 2015.

[10] T. Shin, Y. S. Kim, K. An, and S. K. Lee, "Transfer path analysis of rumbling noise in a passenger car based on in-situ blocked force measurement," Applied Acoustics, vol. 149, pp. 1-14, 2019.

[11] K. Wienen, M. Sturm, A. T. Moorhouse, and J. W. R. Meggit, "Robust NVH engineering using experimental methodssource characterization techniques for component transfer path analysis and virtual acoustic prototyping," SAE International Journal of Advances and Current Practices in Mobility, vol. 1, no. 4, pp. 1766-1778, 2019.

[12] D. De Klerk, D. J. Rixen, and S. N. Voormeeren, "General framework for dynamic substructuring: history, review and classification of techniques," AIAA Journal, vol. 46, no. 8, pp. 1169-1181, 2008.

[13] W. I. I. Mirza, M. N. Abdul Rani, M. A. Ayub, and M. A. Yunus, "Innovative FRF measurement technique for frequency based substructuring method," AIP Conference Proceedings, vol. 1952, no. 1, Article ID 020010, 2018.

[14] D. De Klerk and A. Ossipov, "Operational transfer path analysis: theory, guidelines and tire noise application," $M e$ chanical Systems and Signal Processing, vol. 24/, no. 7, pp. 1950-1962, 2010.

[15] D. Vaitkus, D. Tcherniak, and B. Jonas, "Application of vibroacoustic operational transfer path analysis," Applied Acoustics, vol. 154/, pp. 201-212, 2019.

[16] P. Gajdatsy, K. Janssens, and W. Desmet, "Application of the transmissibility concept in transfer path analysis," Mechanical Systems and Signal Processing, vol. 24, no. 7, pp. 1963-1976, 2010.
[17] M. Van Der Seijs, D. De Klerk, and D. J. Rixen, "General framework for transfer path analysis: history, theory and classification of techniques," Mechanical Systems and Signal Processing, vol. 68-69, pp. 217-244, 2016.

[18] M. Ambardekar, A. Yogesh, and S. Naidu, "A robust solution for a power-train mounting system for automotive $\mathrm{NVH}$ refinements," SAE Technical Papers, 2015.

[19] J. Park, J. Hwang, J. Kim, and J. Lee, "Engine mounting system stiffness optimises handling, NVH performance," Auto Tech Review, vol. 5, pp. 32-37, 2016.

[20] W.-B. Shangguan, X.-A. Liu, Z.-P. Lv, and S. Rakheja, "Design method of automotive powertrain mounting system based on vibration and noise limitations of vehicle level," Mechanical Systems and Signal Processing, vol. 76-77, pp. 677-695, 2016.

[21] C. Jung, H. Kim, H. Oh, K. Hwang, and H. Park, "Optimization of bushing stiffness using numerical approximation model to improve automotive $\mathrm{NVH}$ performance," $S A E$ Technical Paper Series, vol. 2017, 2017.

[22] K. Agarwal, S. Hazra, and V. Kolage, "Virtual analysis of engine mount stiffness and stopper gap tuning for better $\mathrm{NVH}$ performance," SAE Technical Paper, 2017.

[23] R. Abedi, A. H. Shamekhia, and A. Rahi, "Optimization approach to passive engine mounting system for reducing automotive vibrations," SAE Technical Paper, 2019.

[24] W. Cheng, Y. Lu, and Z. Zhang, "Tikhonov regularizationbased operational transfer path analysis," Mechanical Systems and Signal Processing, vol. 75, pp. 494-514, 2016.

[25] C. Yang, Y. Wang, H. Guo, J. Lv, N. Lu, and H. Qi, "Vibration load and transfer path identification of vehicle using inverse matrix method based on singular value decomposition," Proceedings of the Institution of Mechanical Engineers. Part D, Journal of Automobile Engineering, vol. 234, no. 6, pp. 1703-1713, 2020. 